$\mathrm{Oz}$

Volume 4

Article 3

$1-1-1982$

\title{
A Memorial to Those Who Fought in the War Everyone Wants to Forget
}

David H. Bell

Follow this and additional works at: https://newprairiepress.org/oz

(c) (i) $\Theta \Theta$

This work is licensed under a Creative Commons Attribution-Noncommercial-No Derivative Works 4.0 License.

\section{Recommended Citation}

Bell, David H. (1982) "A Memorial to Those Who Fought in the War Everyone Wants to Forget," Oz: Vol. 4. https://doi.org/10.4148/2378-5853.1034

This Article is brought to you for free and open access by New Prairie Press. It has been accepted for inclusion in Oz by an authorized administrator of New Prairie Press. For more information, please contact cads@k-state.edu. 


\section{A Memorial to Those Who Fought in the War Everyone Wants to Forget}

David H. Bell

The spirit has poured himself into everything, even into organic matter, he is present in metal and stone.

\section{Carl Jung}

Sigmund Freud once compared the mind and psyche of man to the city of Rome. Just as Rome developed by building upon, modifying, submerging, and eliminating gradually through time architectural and urban fragments, so does memory work by a sedimentation of experience to create a self for each person. But one can neither freeze an individual person nor Rome at any point during their histories and assume with absolute certainty that either is represented with authority in that temporal accident. To say that anything is complete, fixed and unquestionably determinable at any "now" is an illusion necessary to cultural stability. This entry in the Vietnam Veterans Memorial Competition evolved as a collection of hypothesized architectural and landscape fragments among which there is never more than an ephemeral connection. I believe that, as designers, observers, and users of architecture, we can see forms and spaces combining in certain relationships and that we choose to assign meaning to these relationships, but these meanings have neither permanence nor do they speak with authority.

Yet even as we question the validity of notions of permanence in the evanescent plurality of the modern world, we know or believe that there are some things in our world which

8 do endure, which maintain their
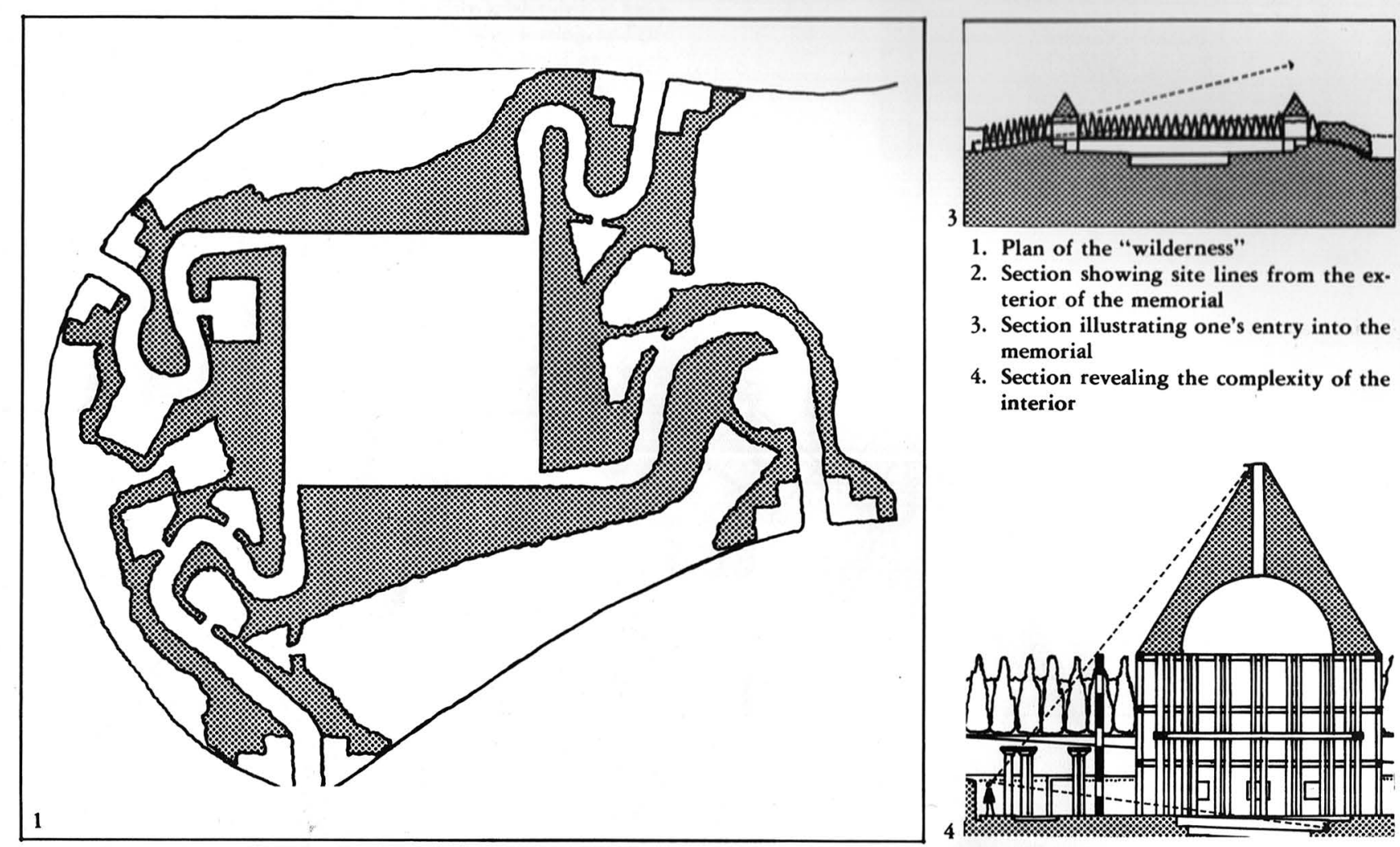

1. Plan of the "wilderness"

2. Section showing site lines from the exterior of the memorial

3. Section illustrating one's entry into the memorial

4. Section revealing the complexity of the interior
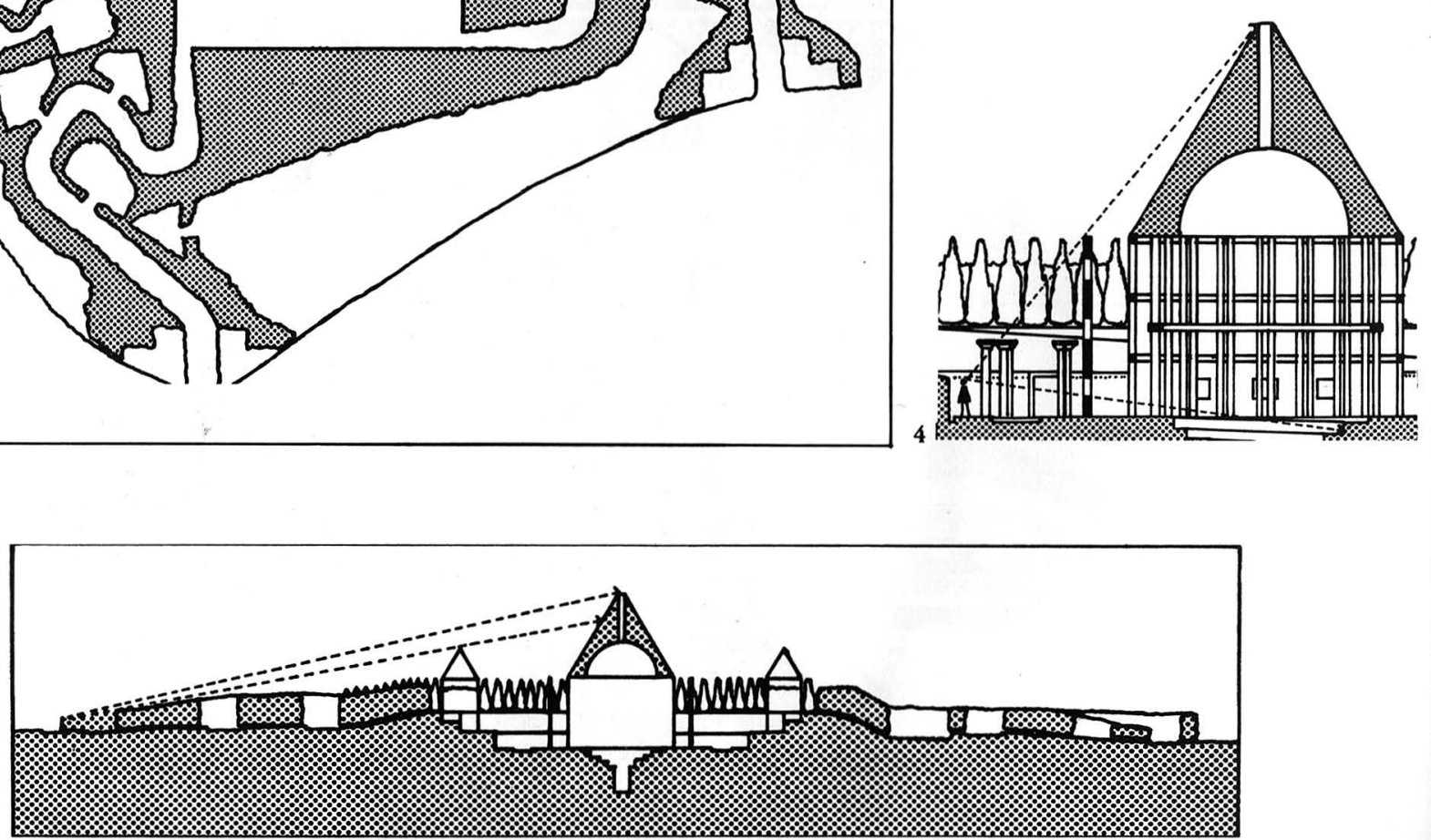

shape in the space of meaningfulness. The ancients believed that the world, despite its apparent mutability, was composed harmoniously of four eternal elements: earth, air, fire and water. In our own time (and with a philosophical rigor that defies abbreviation) Martin Heidegger has put forth in phenomenological terms a vision of the world as also made up of an eternal fourfold: earth, sky, divinity, and man's mortality. The combination of these simple entities in a fourfold makes up a fifth; i.e., the world, one that is incessantly changing but nonetheless has permanence. This idea has provided the 

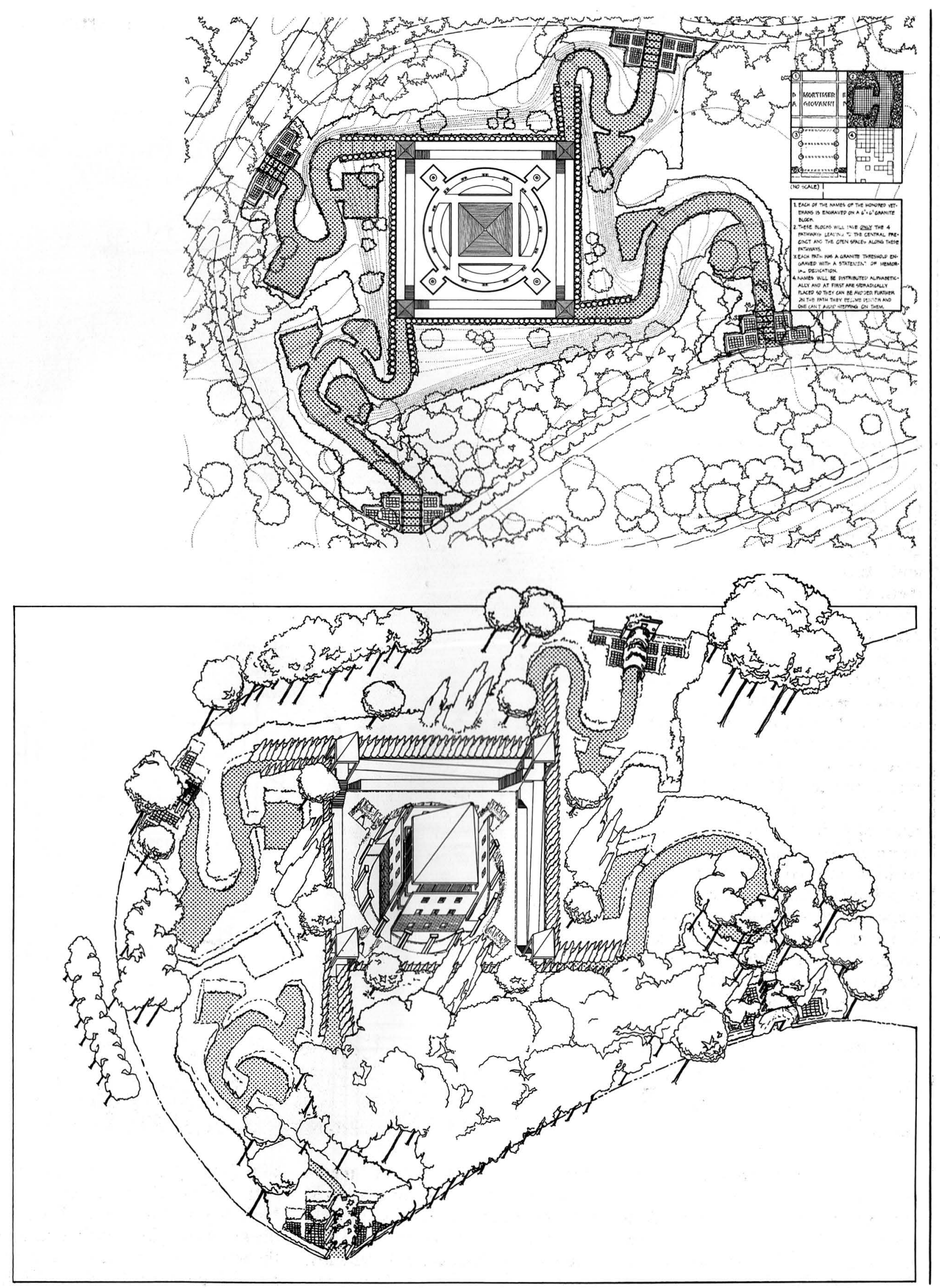


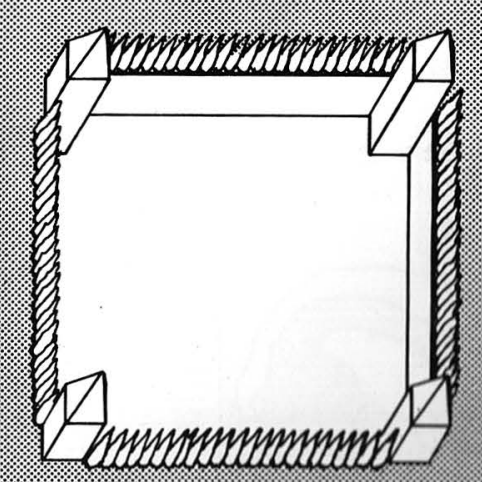

thematic basis for the design of the Vietnam Veterans Memorial illustrated here in both literal and figurative senses.

America itself is the willful creation of a world, an idea carved out of nature. The monumentality of Washington, D.C., where this memorial is to be placed, represents this idea. For this memorial a "wilderness" is created (Figure 1) on a site in Constitution Gardens near the Lincoln Memorial. This "wilderness" contrasts with the geometric regularity and "permanence" of the architectural forms contained by its interior. It was also felt that, rather than challenge directly, or become completely submissive to, the immediate, strong physical context of the Mall and Constitution Avenue, the Vietnam Veterans Memorial would acquiesce to that context when viewed from the exterior by appearing to be a modest pyramid. But the more one becomes involved with it, the scheme simultaneously reveals itself as much more complex and the world outside becomes gradually less apparent (Figures 2-4). From Boulée was borrowed the idea that a memorial ought to be a sunken building, thus suggesting burial and the ritual of the funeral. The fourcorner pavilions and walls which enclose the sunken memorial precinct suggest a fortress. Vertically proportioned evergreens around the perimeter might suggest soldiers standing eternally at attention if seen out of the corner of the eye 10 (Figure 7).
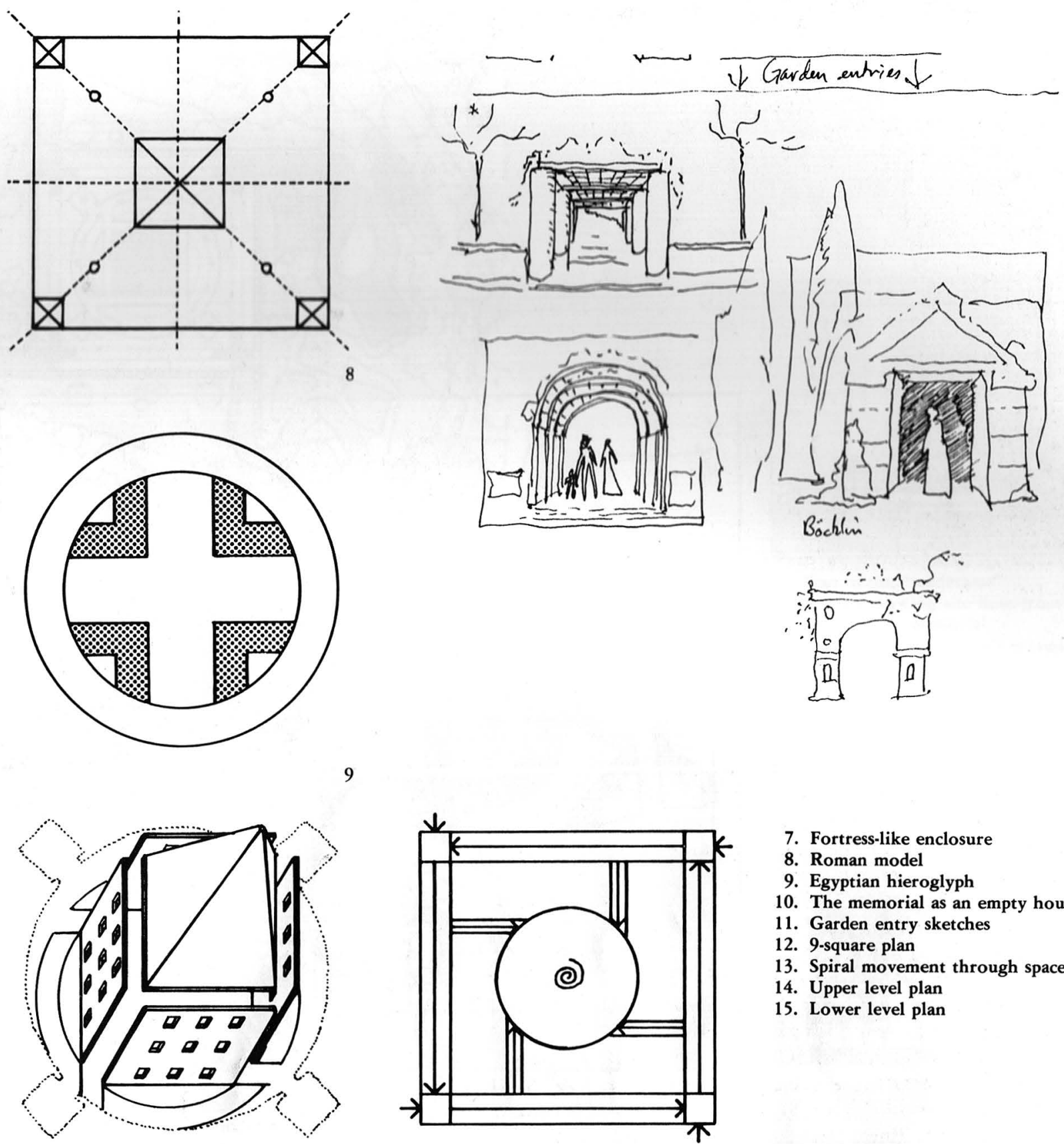

7. Fortress-like enclosure

8. Roman model

9. Egyptian hieroglyph

10. The memorial as an empty house

11. Garden entry sketches

12. 9-square plan

13. Spiral movement through space

14. Upper level plan

15. Lower level plan

10
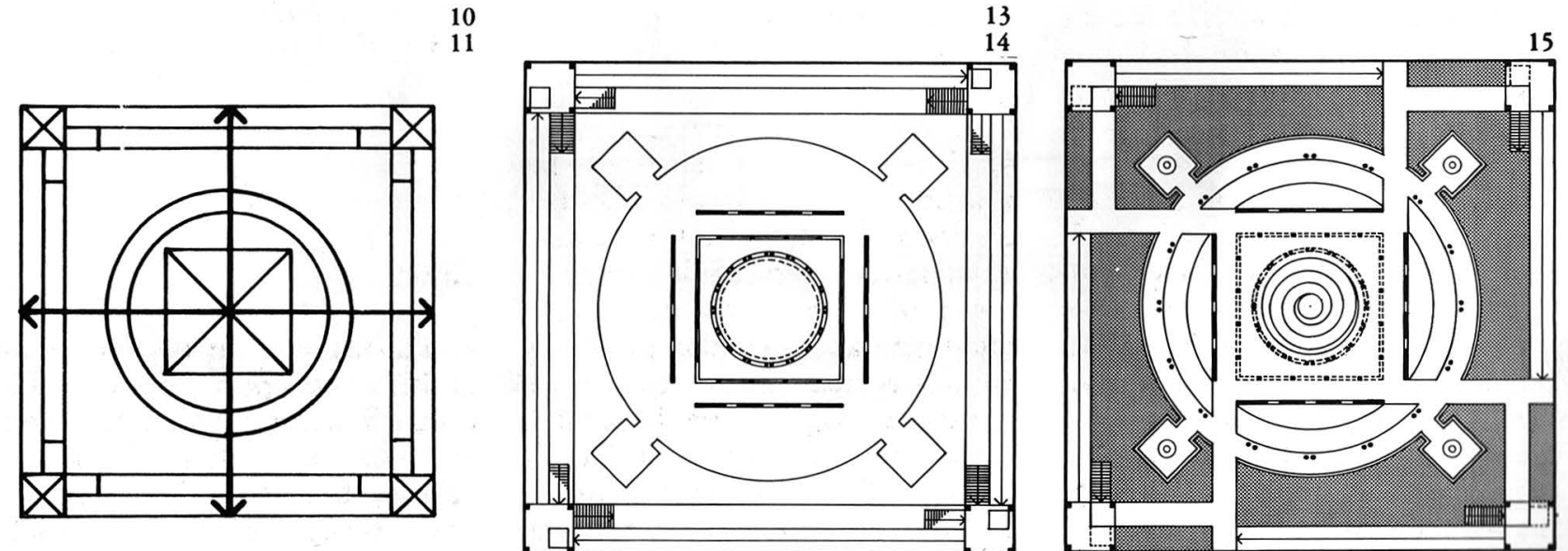


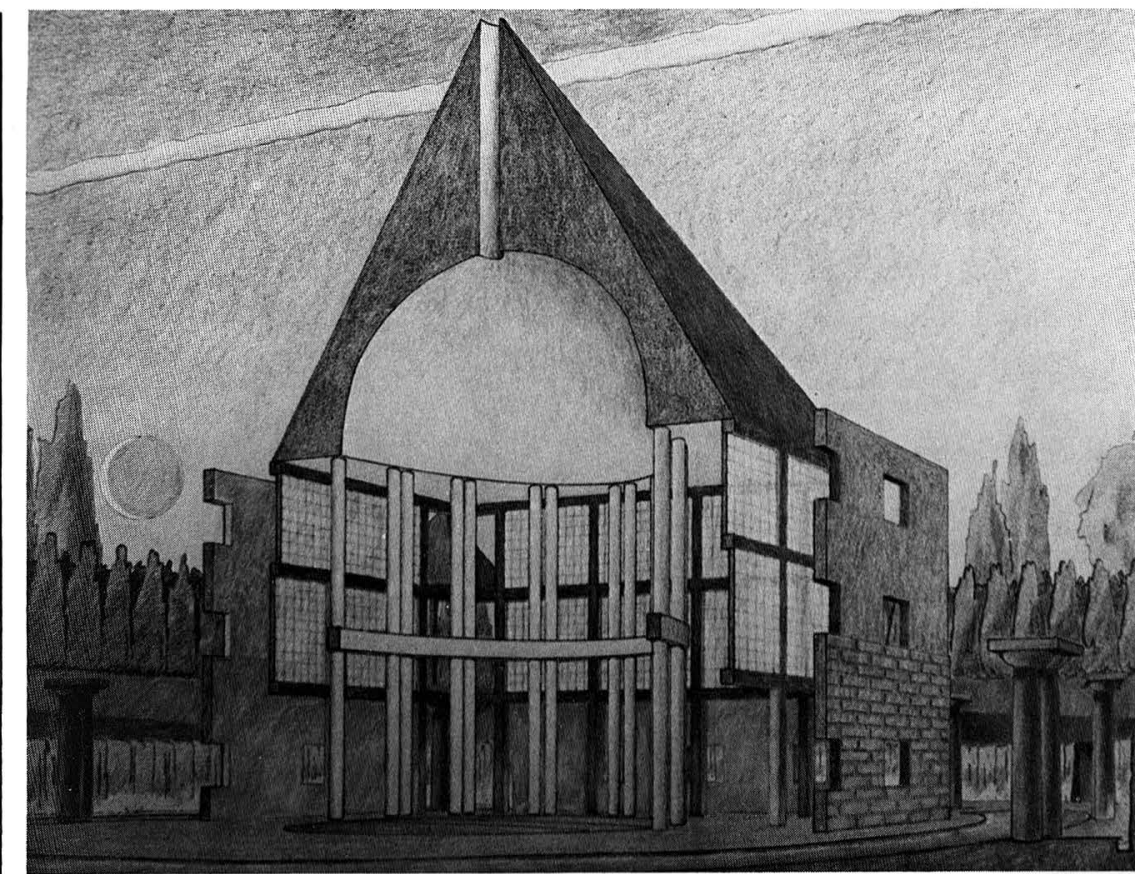

Sectional perspective of the memorial building

The notion that this memorial might be conceived as a kind of a world is rendered more poignant by the fact that soldiers in Vietnam referred to America not simply as home but as "the world." This scheme elaborates on three conceptual images which suggest different conditions of world. Resolving the tensions between circle and square or subdividing a circular periphery into quadrants was the traditional Roman way of consecrating a place and establishing a world (Figure 8). Figure 9 shows a cruciform pattern within a circle which was the ancient Egyptian hieroglyph for both city and world. That this memorial might be seen or envisaged as a city may be significant since the enormity of human loss that it represents is equal to the population of a small city the size of Troy, New York (almost 60,000). Given the American tradition of individualism the house as an image of the world seems especially appropriate. But this house (Figure 10), the symbol of the individual, is an empty house. It is a reminder only of the possibility, not the actuality, of habitation. It contains no life to be lived. Death, regardless of circumstances, is always an individual event.

The memorial is entered through one of four small gardens (Figures $5,6,11)$ at the periphery of the site and proceeds along a curving pathway to the interior. The four pathways are paved with 6" x 6" granite stones. Upon each of these stones is engraved the name of one of the honored veterans. Walking along this path one must keep one's head bowed in order to read these names.

There are quite a few more ideas which led to the formation of this scheme, but in the interests both of brevity and a desire not to obscure its more readily palpable aspects as portrayed by the drawings, I conclude with an illustration proposing the ideas that architecture in a gentle way ought to be difficult; it ought to resist easy resolution. It ought to force the observer into a confrontation with the architectural

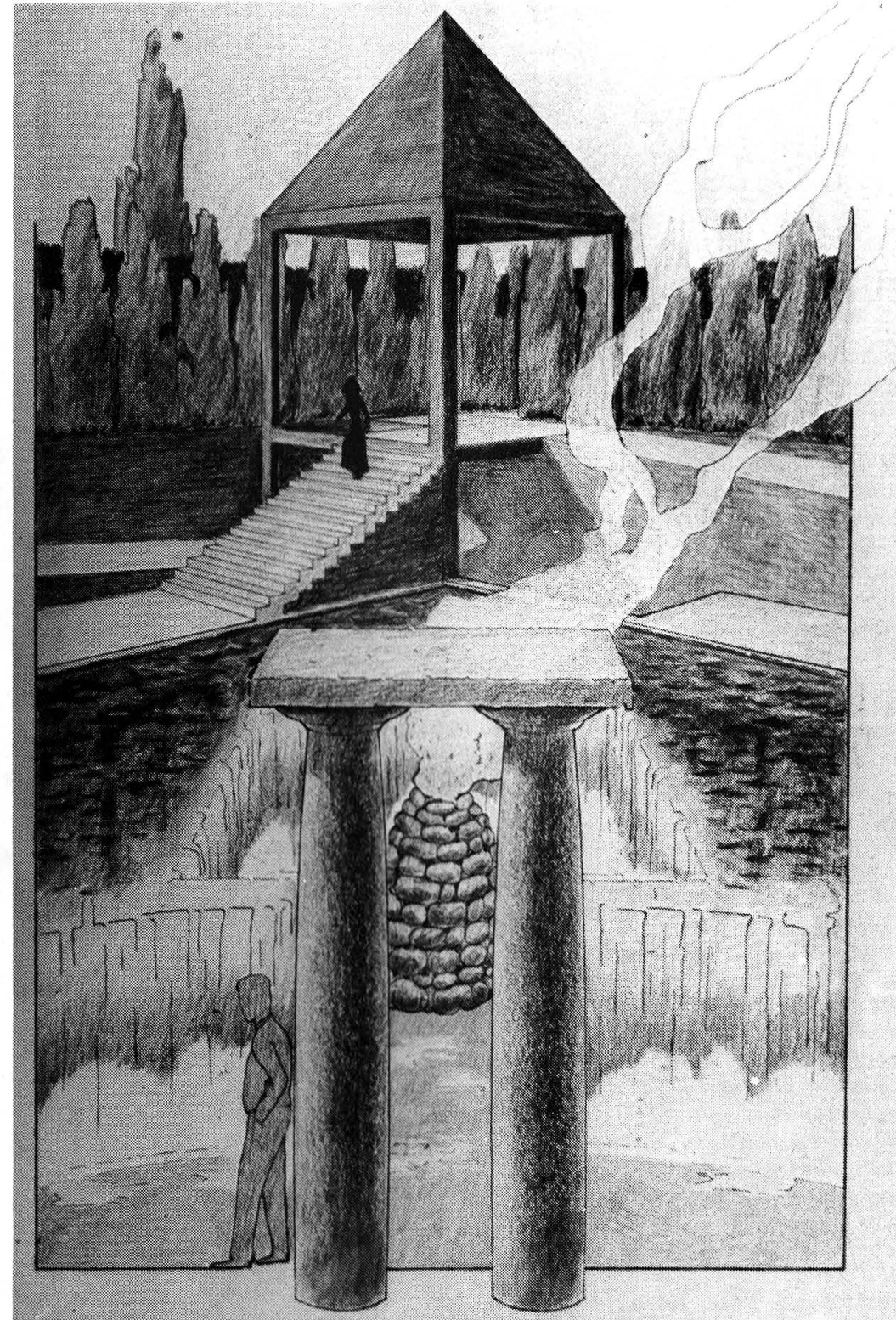

View of an entry pavilion from the sunken precinct

object.

As an example, the central precinct of this scheme possesses an unreconciled difference between the formal and spatial orders. There the primary formal parti is a strongly axial version of the traditional 9-square plan (Figure 12). On the other hand, space, and particularly one's movement through it, (Figure 13), is tangentially related to the central feature, rather than congruent with any of its organizational axes, it is inconclusive: its endpoint is indeterminate. 